\title{
A novel technique of submandibular intubation with a camera cable drape: a case report
}

\author{
Hye Joo Yun', Seung-Hyun Rhee², Joo-Young Park ${ }^{3}$, Yeon Su Chae ${ }^{3}$, Jin-Hee Han², Seung-Hwa Ryoo², \\ Kwang-Suk Seo², Hyun Jeong Kim², Myong-Hwan Karm² \\ 'Department of Anesthesiology and Pain Medicine, Eunpyeong St. Mary's Hospital, College of Medicine, The Catholic University of \\ Korea, Seoul, Korea \\ ${ }^{2}$ Department of Dental Anesthesiology, Seoul National University Dental Hospital, Seoul, Korea \\ ${ }^{3}$ Department of Oral and Maxillofacial Surgery, Seoul National University Dental Hospital, Seoul, Korea
}

\begin{abstract}
Submental or submandibular intubation has been reported to cause fewer complications than tracheostomy. However, the risk of infection is always inherent because oral wounds are exposed to microbial flora and bacteria in the oral cavity. A novel technique of submandibular intubation was devised to reduce infection and injury to the soft tissues. We would like to report a novel safe technique that can be performed in patients requiring submental or submandibular intubation. This is the first report of submandibular intubation using a sterile disposable camera cable drape. This novel technique of submandibular intubation is safer, more sterile, easier, and less invasive than conventional submandibular intubation.
\end{abstract}

Keywords: Panfacial Fracture; Reinforced Endotracheal Tube; Sterile Disposable Camera Cable Drape; Submandibular Intubation.

This is an Open Access article distributed under the terms of the Creative Commons Attribution Non-Commercial License (http://creativecommons.org/licenses/by-nc/4.0/) which permits unrestricted non-commercial use, distribution, and reproduction in any medium, provided the original work is properly cited.

\section{INTRODUCTION}

Maintaining a secure airway is the most important part of general anesthesia during panfacial surgery. Orotracheal intubation (OTI) may interfere with surgical access and maxillomandibular fixation during the reconstruction. In most maxillofacial surgeries in which dental occlusion needs to be assessed intraoperatively, nasotracheal intubation (NTI) is the preferred route. However, NTI is not recommended in cases of a nasal or LeFort II/III fracture with or without a cerebrospinal fluid leak due to unintended positioning of the endotracheal tube (ETT) into the intracranial space via a skull base fracture $[1,2]$.
Therefore, airway management in panfacial fracture surgery is challenging for anesthesiologists.

Alternatives are needed for patients who cannot undergo NTI or OTI, commonly used in general anesthesia for dental surgery. Tracheostomy is an alternative to airway management for panfacial fractures and is commonly performed. However, if prolonged maintenance of the airway or ventilation is not needed, then tracheostomy is not an appropriate alternative [3].

In 1986, Francisco Hernandez Altemir introduced submental intubation to avoid tracheostomy in selected oral and maxillofacial cases [4,5]. Although several submental or submandibular intubation (SMI) technoques have been proposed over the last 30 years, the best

Received: May 19, 2020 - Revised: June 15, 2020 - Accepted: June 16, 2020

Corresponding Author: Myong-Hwan Karm, Department of Dental Anesthesiology, Seoul National University Dental Hospital, 101, Daehakro, Jongno-gu, Seoul 03080, Korea.

Tel: +82-2-2072-3847 Fax: +82-2-766-9427 E-mail: karmmh@snu.ac.kr

Copyright(c) 2020 Journal of Dental Anesthesia and Pain Medicine 


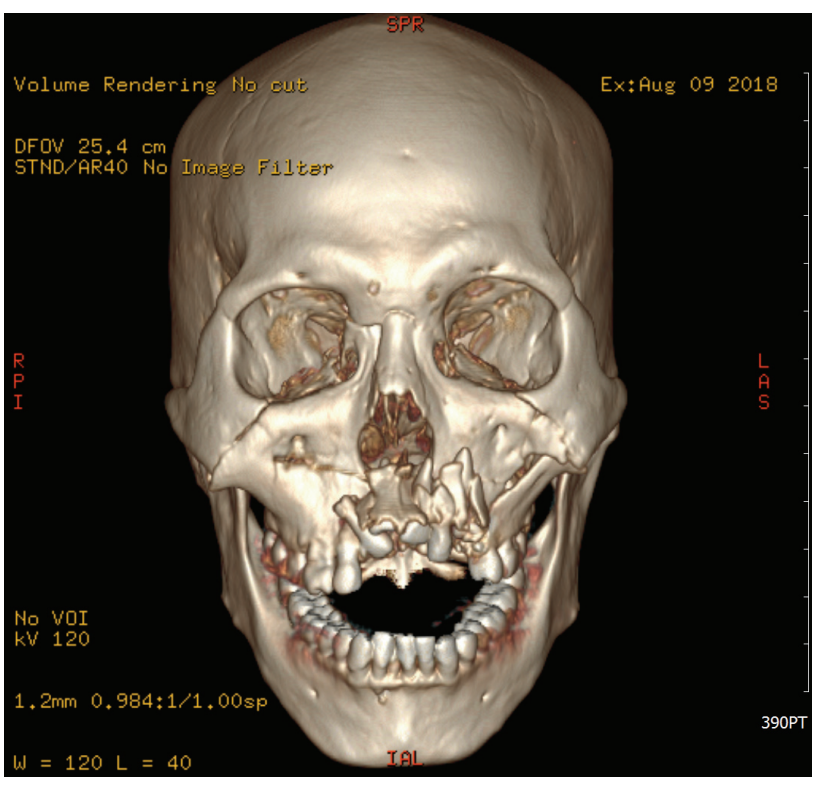

Fig. 1. Pre-operative 3-dimensional reconstructed computed tomography image of the patient

technique is not yet evident $[6,7]$. We report a novel SMI technique using a sterile disposable camera cable drape (SDCCD) to minimize the infection and injury caused by surgical intubation. This case suggests that SMI with an SDCCD can be an appropriate alternative to tracheostomy. Additionally, we suggest that a novel technique of SMI with an SDCCD is safer, easier, and less invasive compared to conventional SMI without SDCCD.

\section{CASE REPORT}

A 51-year-old man injured in an accident 5 days previously was admitted to the oral and maxillofacial surgery department. He sustained a facial injury from a falling soccer goal frame and was diagnosed with LeFort I fracture (left), LeFort II fracture (both), infraorbital wall fracture, maxillary anterior alveolar fracture, maxillary sinus anterior wall fracture, and a lower lip laceration (Fig. 1). Additionally, he had severe advanced periodontitis and most teeth were mobile regardless of tooth injuries, which made intermaxillary fixation difficult using conventional tooth-supported arch bars, and detecting reference points for maxillary advancement to

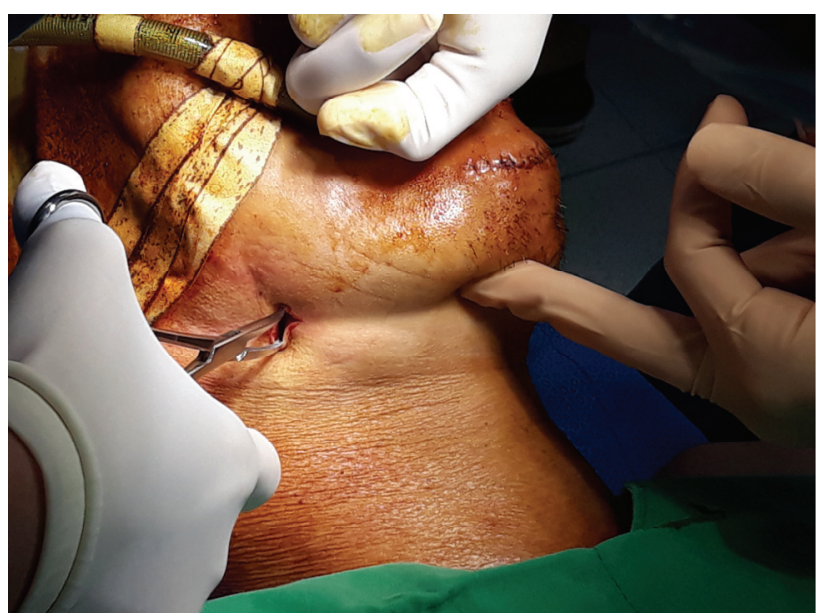

Fig. 2. Submandibular incision and blunt dissection close to the lower border of mandible.

reduce the depressed maxilla was particularly difficult. To achieve the best results for open reduction and internal fixation perioperatively, SMI of the ETT was required rather than OTI or NTI.

Prior to anesthesia induction, the connector of a reinforced ETT (Lo-Contour Oral/Nasal Tracheal Tube Cuffed, Coviden Mallinckrodt ${ }^{\mathrm{TM}}$, Dublin, Ireland) was removed and returned to its normal position to allow easier passage of the tube into the submandibular tunnel. The patient was monitored using electrocardiography, pulse oximetry, and noninvasive blood pressure measurements. Awake OTI was performed as difficult mask ventilation was expected. During preoxygenation, we performed nebulization with $4 \%$ lidocaine and an intravenous injection of fentanyl $50 \mu \mathrm{g}$ with midazolam $1 \mathrm{mg}$. Subsequently, awake OTI was performed with a 7.5-mm internal diameter (ID) reinforced ETT. After confirming the success of the OTI, thiopental $250 \mathrm{mg}$ and rocuronium $50 \mathrm{mg}$ were administrated intravenously for induction of general anesthesia, following which, the submandibular approach for tracheal intubation was initiated. The patient was scrubbed with betadine and his face and neck were draped. Oxygenation with $100 \% \mathrm{O}_{2}$ was prepared in case of a hypoxic event during the a change from the oral to submandibular approach. A 2 $\mathrm{cm}$ submandibular incision was made two fingers away from the right mandibular border (Fig. 2), and a tunnel 


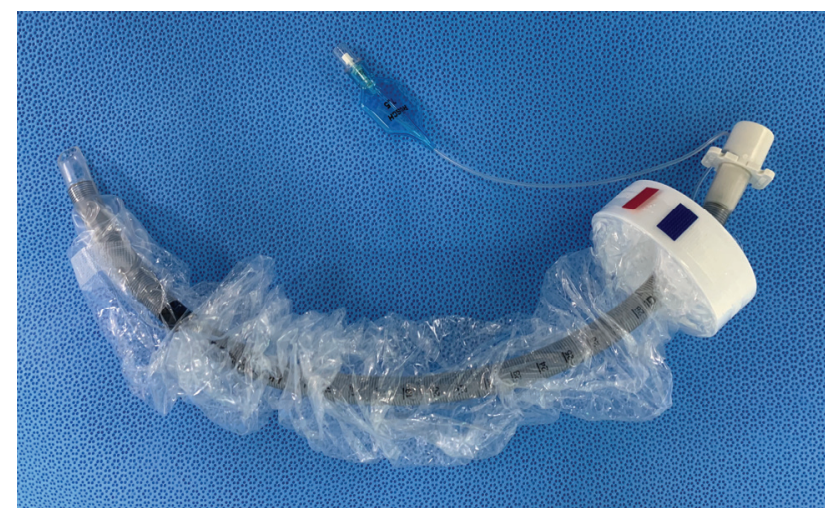

Fig. 3. A reinforced endotracheal tube (internal diameter $7.5 \mathrm{~mm}$ ) is placed inside the Sani-Sleeve ${ }^{\circledR}$ (sterile disposable camera cable drape).

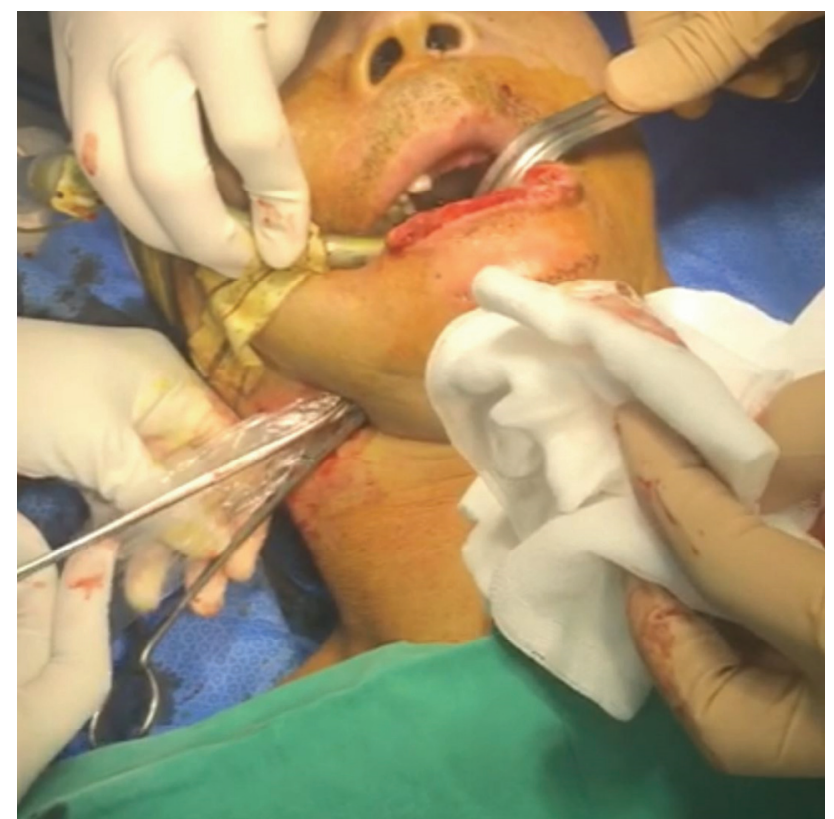

Fig. 4. The Sani-sleeve ${ }^{\circledR}$ is passed with Kelly forceps from the extraoral space to the intraoral cavity, through the submandibular tunnel.

was made to the right mouth floor by blunt dissection using a curved hemostat and dissecting scissors. The Sani-sleeve ${ }^{\mathbb{R}}$ (sterile disposable camera cable drape, Gale Medics, Gwangju, Korea) (Fig. 3) was passed using Kelly forceps through a tunnel extraorally to intraorally (Fig. 4). The pilot 7.5-mm ID reinforced ETT was passed into the Sani-sleeve ${ }^{\circledR}$ tunnel to dilate the space in which the intubated tube would pass (Fig. 5). After confirming a secure space for passage of the intubated tube, the cuff balloon was grasped with the Kelly forceps and pulled out through the Sani-sleeve ${ }^{\circledR}$ tunnel. The ETT was briefly disconnected from the breathing circuit of the ventilator,

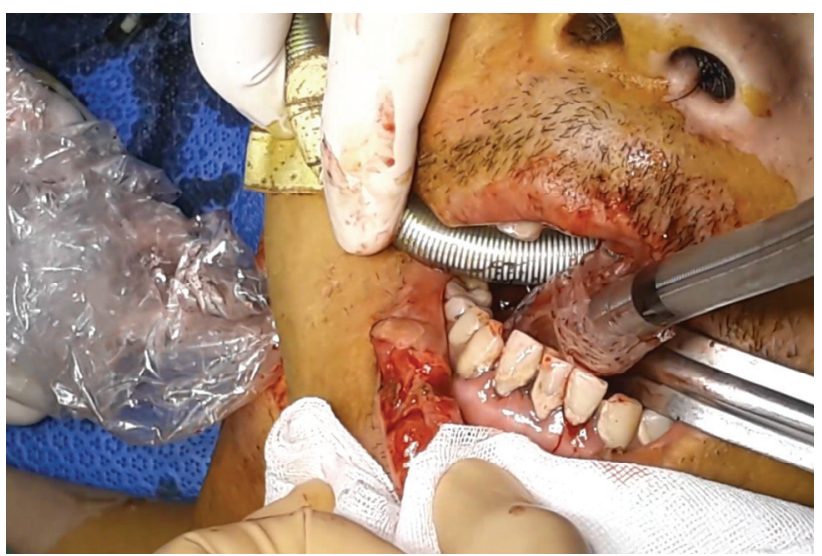

Fig. 5. A 7.5-mm endotracheal tube is inserted through the Sani-sleeve ${ }^{\circledR}$ as a preliminary test.

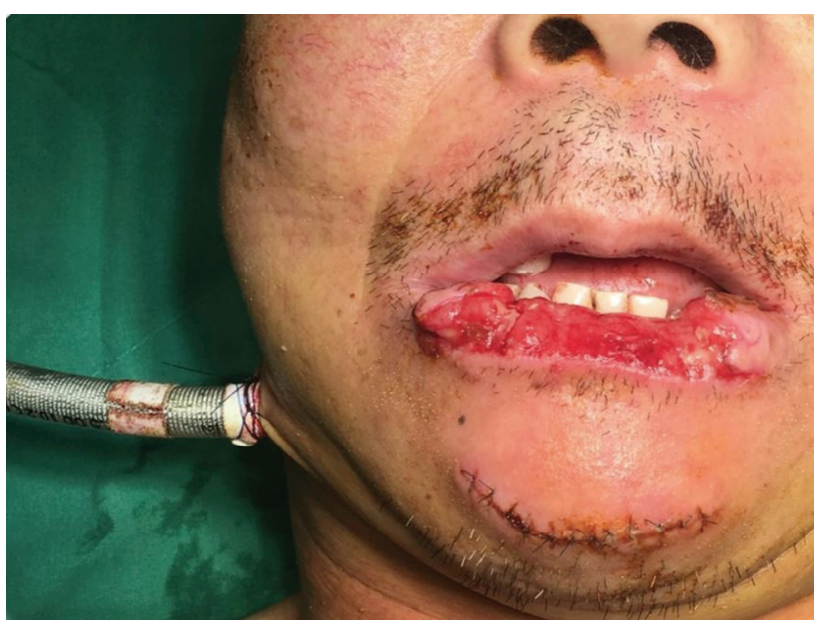

Fig. 6. Submandibular intubation is completed and fixed.

and the tube connector was separated from the ETT. The tube was caught with the tip of the Kelly forceps and removed via the submandibular incision through the Sani-sleeve ${ }^{\circledR}$ tunnel.

Intraorally, the ETT was protected using Magill forceps to prevent accidental extubation during the procedure. The ETT connector was reattached to the tube and breathing circuit of the ventilator. After confirming its tracheal position by capnography and bilateral auscultation of the lung, the tube was fixed to the skin of the submandibular region with nylon sutures (Fig. 6). The SMI procedure is presented as Video 1.

Open reduction and internal fixation, arch bar application (maxilla and mandible), and surgical extraction (\# 11, 12, 13, 14, 15, 21, 22, 23, 24, and 32) 
Video 1. The submandibular intubation process. (https://jdapm.org/src/sm/jdapm-20-155-s001.mp4)

were completed within 7 hours. On completing the surgery, the intubated tube was repositioned again to the oral cavity for closure of the submandibular tunnel. As we decided to extubate, there was no intraoral tissue edema, and the patient's breathing was relatively well maintained. The submandibular tunnel was closed, and extubation was successful without any complications. The patient was discharged from the hospital after 13 days of surgery without any complications.

\section{DISCUSSION}

NTI is the preferred route of endotracheal intubation rather than OTI in maxillofacial surgery. However, tracheostomy is considered when neither OTI nor NTI is possible. In cases that do not require prolonged postoperative ventilation, submental intubation or SMI is a suitable alternative to tracheostomy. Submental/SMI was introduced in 1986 by Hernandez [4] to avoid tracheostomy and to avoid interference to the oral and maxillofacial surgical field.

For submental/SMI, a paramedian approach (61.2\%) is preferred to a median approach (38.4\%) [5]. The median approach was avoided because of potential trauma to Wharton's ducts, interference with the attachment of the genioglossus and geniohyoid muscles, and potential compromise of a snug placement of the tube to the paralingual groove [8]. We preferred SMI to submental intubation to avoid a conspicuous scar and injury to important structures, such as the facial nerve and vessels, lingual nerve, and the excretory duct of the submandibular gland [7,9].

Most published cases of submental intubation or SMI used a hemostat for exteriorization of the ETT. Currently, dilator-based techniques are generally used in clinical practice [10]. However, we introduced a novel technique using Sani-sleeve ${ }^{\mathbb{R}}$ (SDCCD). The concept of using a sterile disposable camera cable drape arose because of concerns regarding infection, especially as the patient's oral hygiene was poor. Infection is the most common complication (2.7-3.5\%) of submental intubation or SMI $[5,11]$. We also preferred SMI because use of the SDCCD could make the intubation process more sterile. Oral wounds are exposed to microbial flora and bacteria in the oral cavity; therefore, the risk of infection is always inherent [12]. In this case, however, we penetrated the SDCCD using a submandibular incision to the floor of the mouth and penetrated the ETT through the SDCCD tunnel. The ETT exposed to oral bacteria does not directly contact the incision site because of the presence of the SDCCD. Therefore, the risk of oral bacteria penetrating the submandibular incision is low. This is particularly important for immune-compromised patients or patients with poor oral hygiene. In such patients, SMI with the sterile disposable camera cable drape can reduce the probability of infection. Furthermore, wrapping the ETT with the SDCCD can render the ETT more sterile than techniques using a hemostat, as the free end of the ETT passes through the SDCCD instead of the incised tissue contaminated with saliva.

Another advantage of using the SDCCD is that aspiration inside the ETT is prevented. With conventional techniques, when the ETT is passed through the submandibular tunnel without an SDCCD, blood or soft tissue may inadvertently enter the tube. However, small amounts of blood or soft tissue entering the distal end of the ETT can be avoided with this technique.

We also expect that SMI using the SDCCD can reduce injury to submandibular soft tissue compared to techniques using a hemostat or dilator. Passing the hard ETT or equipment as a guide through the submandibular tunnel may damage the submandibular soft tissue. However, there is no direct friction with the soft tissue, and smooth passage is possible with the aforementioned technique as the ETT or the equipment is encased within the SDCCD.

Several technical studies have described ways to avoid 
the complications associated with the passage of the ETT from the oral cavity to the submandibular region. However, this is the first case in which SMI was performed using an SDCCD. This novel technique of SMI can reduce infection, aspiration, and injury to the soft tissues. We show that SMI using an SDCCD can be a suitable alternative to tracheostomy for panfacial fractures.

\section{AUTHOR ORCOIDS}

Hye Joo Yun: https://orcid.org/0000-0003-3913-6960

Seung-Hyun Rhee: https://orcid.org/0000-0001-6210-1796

Joo-Young Park: https://orcid.org/0000-0002-0333-6349

Yeon Su Chae: https://orcid.org/0000-0002-1818-2047

Jin-Hee Han: https://orcid.org/0000-0002-1611-6089

Seung-Hwa Ryoo: https://orcid.org/0000-0002-7442-8531

Kwang-Suk Seo: https://orcid.org/0000-0001-5906-0639

Hyun Jeong Kim: https://orcid.org/0000-0002-9265-7549

Myong-Hwan Karm: http://orcid.org/0000-0002-7494-4747

\section{AUTHOR GONIRBDUIONS}

Hye Joo Yun: Visualization, Writing - original draft

Seung-Hyun Rhee: Visualization, Writing - original draft

Joo-Young Park: Conceptualization, Writing - original draft, Visualization

Yeon Su Chae: Visualization

Jin-Hee Han: Visualization

Seung-Hwa Ryoo: Visualization

Kwang-Suk Seo: Supervision

Hyun Jeong Kim: Supervision

Myong-Hwan Karm: Conceptualization, Supervision, Writing - review

\& editing

ACKNOWLEDGMENTS: The authors would like to thank Charles Holt of Columbia University, College of Dental Medicine for the English language review.

DISCLOSURE: The authors declared no competing interests.

INFORMED CONSENT: This study adhered to the tenets of the Declaration of Helsinki. The patient signed informed consent for the publication of this report and any associated images.

\section{REFERENCES}

1. Caubi AF, Vasconcelos BC, Vasconcellos RJ, de Morais $\mathrm{HH}$, Rocha NS. Submental intubation in oral maxillofacial surgery: review of the literature and analysis of 13 cases. Med Oral Patol Oral Cir Bucal 2008; 13: E197-200.

2. Mak PH, Ooi RG. Submental intubation in a patient with beta-thalassaemia major undergoing elective maxillary and mandibular osteotomies. Br J Anaesth 2002; 88: 288-91.

3. Youn GH, Ryu SY, Oh HK, Park HJ, Jung S, Jeong S, et al. Endotracheal intubation using submandibular approach for maxillofacial trauma patients: report of 2 cases. J Korean Dent Soc Anesthesiol 2014;14:227-32.

4. Altemir FH. The submental route for endotracheal intubation - a new technique. J Max Fac Surg 1986; 14: 64-5.

5. Lim D, Ma BC, Parumo R, Shanmuhasuntharam P. Thirty years of submental intubation: a review. Int $\mathrm{J}$ Oral Maxillofac Surg 2018; 47: 1161-5.

6. Oshima N, Shiraishi T, Kawauchi T, Oba J, Sato D, Fujiki $\mathrm{M}$, et al. A simple and reliable submental intubation technique for maxillofacial fractures. J Craniofac Surg 2018; 29: $1952-5$

7. Stoll P, Galli C, Wachter R, Bähr W. Submandibular endotracheal intubation in panfacial fractures. J Clin Anesth 1994; 6: 83-6.

8. Emara TA, El-Anwar MW, Omara TA, Anany A, Elawa IA, Rabea MM. Submental intubation versus tracheostomy in maxillofacial fractures. Oral Maxillofac Surg 2019; 23: 337-41.

9. Anwer HM, Zeitoun IM, Shehata EA. Submandibular approach for tracheal intubation in patients with panfacial fractures. Br J Anaesth 2007; 98: 835-40.

10. Ujam A, Perry M. Minimally traumatic submental intubation: a novel dilational technique. Eur J Trauma Emerg Surg 2017; 43: 359-62.

11. Jundt JS, Cattano D, Hagberg CA, Wilson JW. Submental intubation: a literature review. Int J Oral Maxillofac Surg 2012; 41: 46-54.

12. Belusic-Gobic M, Zubovic A, Cerovic R, Dekanic A, 
Marzic D, Zamolo G. Multivariate analysis of risk factors for postoperative wound infection following oral and oropharyngeal cancer surgery. J Craniomaxillofac Surg 2018; 46: 135-41. 